\title{
Electron Impact Ionization Mass Spectra of 3-Amino 5,6-Dimethoxyl-2-Methyl Quinazolin-4-(3H)-One Derivative
}

\author{
Osarumwense Peter Osarodion ${ }^{1, *}$, Edema Mary Orile², UsifohCyril Odianosen ${ }^{3}$ \\ ${ }^{1}$ Department of Chemical Sciences, Ondo State University of Sciences and Technology, Okitipupa, Ondo State, Nigeria \\ ${ }^{2}$ Provost Office, College of Education, Warri, Delta State, Nigeria \\ ${ }^{3}$ Faculty of Pharmaceutical Chemistry, University of Benin, Benin City, Nigeria
}

\section{Email address:}

osarodion.peter@yahoo.com (O. P. Osarodion)

${ }^{*}$ Corresponding author

\section{To cite this article:}

Osarumwense Peter Osarodion, Edema, Mary Orile, Usifoh Cyril Odianosen. Electron Impact Ionization Mass Spectra of 3-Amino 5,6Dimethoxyl-2-Methyl Quinazolin-4-(3H)-One Derivative. American Journal of Materials Synthesis and Processing.

Vol. 4, No. 2, 2019, pp. 62-67. doi: 10.11648/j.ajmsp.20190402.12

Received: June 6, 2019; Accepted: July 8, 2019; Published: August 7, 2019

\begin{abstract}
Background: The synthesis of novel heterocyclic derivatives has attracted considerable attention. The explosive growth of heterocyclic chemistry is emphasized by the large number of research publications, monographs, and reviews. The heterocyclic organic compounds are extensively disseminated in natural and synthetic medicinal chemistry and are vital for human life. Looking at the previous studies on quinazolinones derivatives, only limited informationis available on their mass spectral along with the preparation of novel quinazolin-4-(3H)-one derivatives. Objective: Objective of this study, was to synthesize a novel 2-Methyl-6, 7-dimethoxy-quinazolin-4-one was synthesized via the reaction between 2-Methyl-6, 7dimethoxy-benzo-1,3-oxazin-4-one andhydrazine hydrate and study their electron impact ( EI ) mass spectral fragmentation. Method: The condensation of 2-amino-methyl-4, 5-dimethoxybenzoate with acetic anhydride yielded the cyclic compound 2methyl-4, 5-disubstituted-1, 3-benzo-oxazine-4-one which further produce a novel 2,3-disubstituted quinazolin-4 ones via the reaction with hydrazine hydrate. The compounds synthesized were unequivocally confirmed by means of Infrared, Nuclear Magnetic Resonance $\left({ }^{1} \mathrm{H}\right.$ and $\left.{ }^{13} \mathrm{C}\right)$, Gas Chromatography Mass Spectrophotometer and Elemental analysis. Discussion: The molecular ion of $\mathrm{m} / \mathrm{z} 235$ fragment to give $\mathrm{m} / \mathrm{z} 220$ by loss of $-\mathrm{NH}$ group. The ion of $\mathrm{m} / \mathrm{z} 220$ was broken to give $\mathrm{m} / \mathrm{z} 206$ by losing $\mathrm{CH}_{2}$ group and fragment to $\mathrm{m} / \mathrm{z} 177$ by loss of $\mathrm{HCO}$. This fragmented to $\mathrm{m} / \mathrm{z} 162$ by loss of $-\mathrm{CH}_{3}$ group and then $\mathrm{m} / \mathrm{z}$ 136 by loss of CN group. The loss of $\mathrm{O}$ gave $\mathrm{m} / \mathrm{z} 120$ which fragment to give $\mathrm{m} / \mathrm{z} 93$ by loss of $-\mathrm{HCN}$ and finally gave $\mathrm{m} / \mathrm{z} 65$ by loss of $\mathrm{CO}$ group. Conclusion: The electron impact ionization mass spectra of compound 2show a weakmolecular ion peak and a base peak ofm/z 235resulting from a cleavage fragmentation. Compound 2 give a characteristic fragmentation pattern. From the study of the mass spectra of compound 2, it was found that the molecular ion had fragmented to the $\mathrm{m} / \mathrm{z} 220$. The final fragmentation led to ion of $\mathrm{m} / \mathrm{z} 93$ and ion of mass $\mathrm{m} / \mathrm{z} 65$, respectively.
\end{abstract}

Keywords: Mass Spectroscopy, Synthesis, Quinazoline-4-One, 2-Methyl 6, 7-Disubtituted 1, 3-Benzo-Oxazine-4-One, Nucleophile, Electron Impact Ionization Mass Spectra

\section{Introduction}

Heterocyclic compounds are cyclic compounds with the ring containing carbon and other elements, the commonest being oxygen, nitrogen and sulphur [1]. Some of the medicinally important heterocyclic compounds are the quinazolines. Quinazoline is a compound made up of two fused six-membered simple aromatic rings, benzene ring and a pirimidine ring. Quinazoline, earlier known as benzo-1 3diazine was first prepared in the laboratory by Gabriel in 1903, although one of its derivatives was known much earlier [2].

Of the many derivatives of quinazoline system known so far, keto-quinazolines also called quinazolinones, are the most important compounds. Depending upon the position of the keto or oxo group, these compounds may be classified into two. The two structural isomers are 2-quinazolinone and 
4-quinazolinone, with the 4-isomer being the most common [3].

Quinazolinone form a large group among the pharmacologically active chemical moieties and are generally of little toxicity without serious side effects to the human body. Quinazolinones are versatile nitrogen heterocyclic compounds, displaying a broad spectrum of biologically and pharmacological activities in animal as well as in human systems. The chemistry and pharmacology of quinazolinones have been of great interest to medicinal chemist [4]. Quinazolin-4-one and its derivatives possess a diverse range of biological activities including analgesic [56], anticancer [7-8] and antidiabetic activity [9-10].

Heterocyclic compounds have a wide range of application: they are predominant among the type of compounds used as pharmaceuticals [11], as agrochemicals and as veterinary products. They also find applications as sentizers, developers, antioxidants, as corrosion inhibitors, as copolymers, dyestuff [12].

Quinazolinone peptides were reported for their antiinflammatory, antioxidant, anthelminthic, antibacterial and antifungal activities [13-14].

Quinazolin-4(3H)- ones with 2,3-substitution are reported to possess significant analgesic, anti-inflammatory [15-16] and anticonvulsant activities [17].

Looking at the previous studies on quinazolinones derivatives, only limited informationis available ontheir massspectral along with the preparation of novelquinazolin4-(3H)-one Derivative. In this study, a novel2-Methyl-6, 7dimethoxy-quinazolin-4-one was synthesized via the reaction between 2-Methyl-6, 7-dimethoxy-benzo-1,3-oxazin-4-one andhydrazine hydrate and study their electron impact ( EI ) mass spectral fragmentation.

\section{Materials and Methods}

\section{General Experimental Procedure}

Reagents and solvents were purchased from sigma-Aldrich chemical supplier in Germany. Melting points were determined on a Kofler hot stage apparatus and are uncorrected. IR spectra were recorded on a Buck scientific IR M500 instrument. The ${ }^{1} \mathrm{H}$ and ${ }^{13} \mathrm{C}$ NMR spectra were recorded in DMSO- $d 6$ at $400 \mathrm{MH}_{\mathrm{z}}$ with HAZ VOLATILE V2.M. Chemical shifts are reported in ppm relative to tetramethylsilane period. Gas chromatography mass (GC/MS) spectra were obtained on a Finingan MAT 44S mass spectrometer operating at electron impact energy of $70 \mathrm{eV}$.Elemental analysis data agreed with the calculated values. Analytical thin layer Chromatography (TLC) was used to monitor the reactions.

\section{Experimental}

Reagents and solvents were purchased from sigma-Aldrich chemical supplier in Germany. Melting points were determined on a Kofler hot stage apparatus and are uncorrected. IR spectra were recorded on a Buck scientific IR M500 instrument. The ${ }^{1} \mathrm{H}$ and ${ }^{13} \mathrm{C}$ NMR spectra were recorded in DMSO at $400 \mathrm{MH}_{\mathrm{z}}$ with HAZ VOLATILE V2.M. Chemical shifts are reported in ppm relative to tetramethylsilane. Gas chromatography Mass spectra were obtained on a HAZ VOLATILE V2.M (400MHz) and chemical shifts are reported in ppm relative to tetramethylsilane as reference standard. Elemental analysis agreed favourably with the calculated values. Analytical thin layer Chromatography (TLC) was used to monitor the reactions.<smiles>[R]C(=O)c1cc([R])c([R])c([R3])c1N</smiles>

Scheme 1:<smiles>[R]c1cc2c(=O)oc(C)nc2c([R])c1[R]</smiles>

(1)

Where: $\mathbf{R}_{1}=\mathrm{OCH}_{3}, \mathbf{R}_{2}=\mathrm{OCH}_{3}$ and $\mathbf{R}_{3}=\mathbf{H}$<smiles>[R]c1cc(C(=O)OC)c(N)c([R])c1[R]</smiles>

Figure 1. Possible Mechanism For Synthesis of Compound 1. 
<smiles>[R]c1cc2c(=O)oc(C)nc2c([R])c1[R]</smiles>

(1)<smiles>[R]c1cc2c(=O)n(N)c(C)nc2c([R])c1[R]</smiles>

(2)

Scheme 2

Possible Mechanism

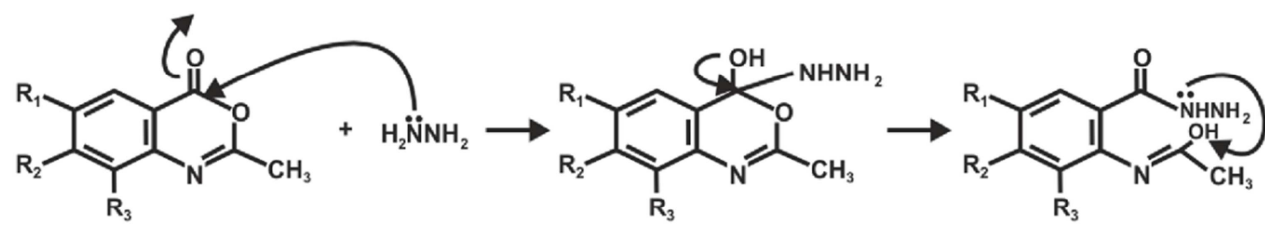<smiles>[R]c1cc2c(=O)n(N)c(C)nc2c([R])c1[R]</smiles>

Figure 2. Possible Mechanism For Synthesis of Compound 2.

\section{Result}

The introduction of 2-Amino substituent is a successful strategy to improve the chemical stability of benzoxazinone. Due to the pharmacological activities of $4(3 \mathrm{H})$ quinazolinone derivatives, 2,3-disubstituted derivatives of quinazoline-4-one was synthesized via the interaction of the benzoxazinone derivative with nitrogen nucleophile with the aim of obtaining more pricise information about the course of the reaction and some interesting pharmaceutical compounds. The reaction of 4,5 -disubstituted derivatives of methylanthranilate and acetic anhydride yielded the cyclic compound 2-methyl-6, 7-dimethoxyl-benzo-1, 3-oxazin-4one. The reaction of this compound with hydrazine hydrate yielded the novel 2, 3-disubstituted quinazoline-4-one.

Table 1. Characterization and Physical data of Synthesized Compounds.

\begin{tabular}{|c|c|c|c|c|}
\hline \multirow{2}{*}{ Compound No } & \multirow{2}{*}{ Solvent } & \multirow{2}{*}{ Formula M. wt } & \multicolumn{2}{|c|}{ Analysis\% Calc/Found } \\
\hline & & & $\mathbf{C}$ & $\mathbf{H}$ \\
\hline 1 & Ethanol & $\begin{array}{l}\mathrm{C}_{11} \mathrm{H}_{11} \mathrm{NO}_{4} \\
(221.209)\end{array}$ & $\begin{array}{l}62.20 \\
62.10\end{array}$ & $\begin{array}{l}5.18 \\
4.98\end{array}$ \\
\hline 2 & Ethanol & $\begin{array}{l}\mathrm{C}_{11} \mathrm{H}_{13} \mathrm{~N}_{3} \mathrm{O}_{3} \\
(235.239)\end{array}$ & $\begin{array}{l}56.11 \\
56.40\end{array}$ & $\begin{array}{l}5.53 \\
5.41\end{array}$ \\
\hline
\end{tabular}

Table 2. ${ }^{13}$ C-NMR of Synthesized Compounds.

Compound No


Table 3. ${ }^{13} \mathrm{C}-\mathrm{NMR}$ of Synthesized Compounds.
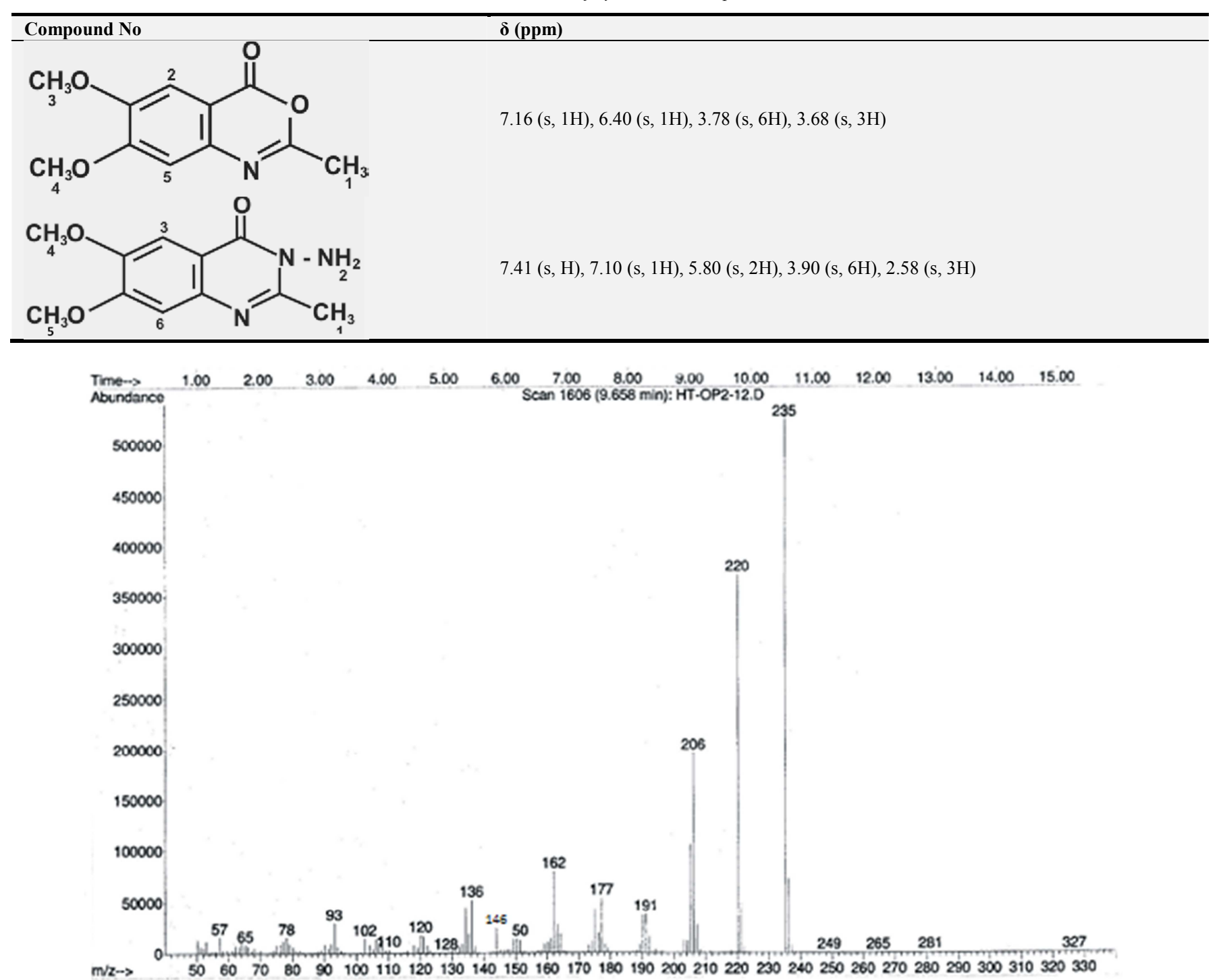

Figure 3. 70Ev Mass Spectrum of compounds 2.

Table 4. EI Mass Spectra (70ev) of Compound, $2 \mathrm{~m} / \mathrm{z}$ (relative intensity, \%).

\begin{tabular}{|c|c|c|c|c|}
\hline Compound & M+ & M- & $\mathbf{m} / \mathbf{z}$ & Other Ions \\
\hline 2 & $\begin{array}{l}{\left[\mathrm{C}_{11} \mathrm{H}_{13} \mathrm{~N}_{3} 0_{3}\right]^{+}} \\
235(100)\end{array}$ & $\begin{array}{l}\mathrm{NH} \\
\mathrm{CH}_{2} \\
\mathrm{HCO} \\
\mathrm{CH}_{3} \\
\mathrm{OH} \\
\mathrm{CN} \\
\mathrm{O} \\
\mathrm{HCN} \\
\mathrm{CO}\end{array}$ & $\begin{array}{l}\left.\mathrm{C}_{11} \mathrm{H}_{12} \mathrm{~N}_{2} \mathrm{O}_{3}\right]^{+} \\
220(70) \\
{\left[\mathrm{C}_{10} \mathrm{H}_{10} \mathrm{~N}_{2} \mathrm{O}_{3}\right]^{+}} \\
206(37) \\
{\left[\mathrm{C}_{9} \mathrm{H}_{9} \mathrm{~N}_{2} \mathrm{O}_{2}\right]^{+\cdot}} \\
177(10) \\
{\left[\mathrm{C}_{8} \mathrm{H}_{6} \mathrm{~N}_{2} \mathrm{O}_{2}\right]^{+\cdot}} \\
162(15) \\
{\left[\mathrm{C}_{8} \mathrm{H}_{6} \mathrm{~N}_{2} 0\right]^{+}} \\
146(1.5) \\
{\left[\mathrm{C}_{7} \mathrm{H}_{6} \mathrm{NO}_{2}\right]^{+}} \\
136(10) \\
{\left[\mathrm{C}_{7} \mathrm{H}_{6} \mathrm{NO}^{+}\right.} \\
120(4) \\
{\left[\mathrm{C}_{6} \mathrm{H}_{5} \mathrm{O}\right]^{+}} \\
93(10) \\
{[\mathrm{C} 5 \mathrm{H} 5]^{+} .} \\
65(2)\end{array}$ & $\begin{array}{l}191(8), 136(10), 102(3), 93(5), 78(3), \\
57(3)\end{array}$ \\
\hline
\end{tabular}




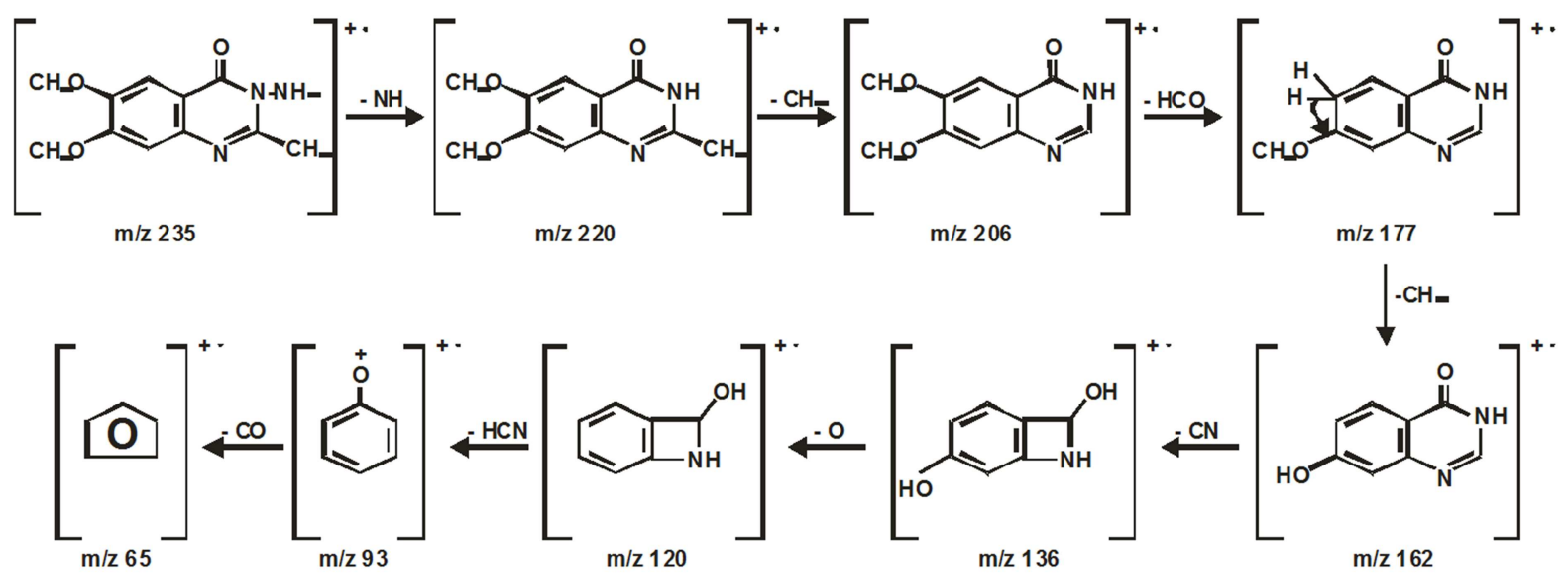

Figure 4. Main Fragmentation Pathway of Compound 2.

\subsection{Characterization of 2-Methyl-4, 5-Disubstituted 1, 3-Benzooxazine-4-One(1)}

${ }^{1} \mathrm{H}$ NMR (400MHz, DMSO) $\delta 7.16(\mathrm{~s}, 1 \mathrm{H}), 6.40(\mathrm{~s}, 1 \mathrm{H})$, $3.78(\mathrm{~s}, 6 \mathrm{H}), 3.68(\mathrm{~s}, 3 \mathrm{H}),{ }^{13}$ (NMR (400MHz, DMSO) $\delta$ $168.28,155.80,149.23,140.28,113.37,100.56,100.05$, 56.94, 56.94, 56.13, 51.93, 16.95: IR $\left(\mathrm{KBr}, \mathrm{cm}^{-1}\right)$ 3381, 3203, 3135, (NHz), 3018 (CH aromatic), 2951, 2871, 2718 (CH aliphatic), 1662 (C=0). Anal. Cal 1159 (c-0) for $\mathrm{C}_{11} \mathrm{H}_{11} \mathrm{N0}_{4}$; C 62.20; H 5.18. Found: C 62.10, H 4.98.

\subsection{Characterization of}

\section{3-Amino-2-Methyl-Quinazoline-4-One(2)}

${ }^{1} \mathrm{H}$ NMR (400 MHz, DMSO) $\delta 7.41(\mathrm{~s}, 1 \mathrm{H}), 7.10(\mathrm{~s}, 1 \mathrm{H})$, $5.80(\mathrm{~s}, 2 \mathrm{H}), 3.90(\mathrm{~s}, 6 \mathrm{H}), 2.58(\mathrm{~s}, 3 \mathrm{H}),{ }^{13} \mathrm{C} \mathrm{NMR}(400 \mathrm{MHz}$, DMSO) $\delta 160.28,155.29,154.57,149.07,143.77,113.65$, 108.24, 105.64, 56.80, 56.63, 22.58, IR (KBr, cm $\left.{ }^{-1}\right) 3301$ $\left(\mathrm{NH}_{2}\right), 1622(\mathrm{C}=0)$, Anal. Cal. for $\mathrm{C}_{11} \mathrm{H}_{13} \mathrm{~N}_{3} \mathrm{O}_{3} ; \mathrm{C} 56.11, \mathrm{H}$ 5.53; Found, C 56.40, H 5.41.

\section{Discussion}

Structural elucidations of compounds synthesized were characterized by correct elemental analysis and careful inspections of spectral data. Looking at the ${ }^{1} \mathrm{H}$ NMR spectra of the compounds synthesized, compound 1 displayed a singlet signal at: $\delta 3.78$ attributed to methoxy group and singlet at $\delta 3.68$ which was due to methyl group. Other singlets appeared at $\delta 7.16$ and 6.40 attributed to aromatic protons. Also, ${ }^{1} \mathrm{H}$ NMR spectrum of compound 2 showed a characteristic signal at $\delta 2.56$ (singlet) corresponding to methyl group and duplet at: $\delta 3.90$ for methoxy group. Two singlets appeared at $\delta 7.41$ and 7.10 attributed to aromatic protons. Another signal appeared at 5.80 which was attributed to the protons of the amino group. For the IR spectra, compound 1 was characterized by absence of $v$ $\mathrm{NH}_{2}$ and presence of $v \mathrm{C}-\mathrm{O}$ stretch in $1101 \mathrm{~cm}^{-1}$ region of the compound. Compound 2 was characterized by absence of $v$ $\mathrm{C}-0$ and presence of $\mathrm{vNH}_{2}$ in $3301 \mathrm{~cm}^{-1}$ region of the compound.

The ${ }^{13} \mathrm{C}$ NMR spectrum of compound 1, revealed signals at $\delta 16.95,51.93$ and 56.13 attributed to methyl and the two methoxy groups respectively, while the aromatic carbon atoms appeared between $\delta$ values $100.05-168.28$ with the carbonyl carbon atom appearing as the highest $\delta$ value of 168.28. Similarly, compound 2 showed signals at $\delta 22.58$, 56.63 and 56.80 attributed to methyl and the two methoxy groups respectively, while the aromatic carbon atoms appeared between $\delta$ values 105.64-160.28, with the carbonyl carbon atom appearing as the highest $\delta$ value of 160.28.

The ${ }^{13} \mathrm{C}$ nuclear magnetic resonance revealed low $\delta$ values for the aliphatic carbons. This is because the alkyl group is electron donating and hence produces a shielding effect which makes the carbon atom to resonate at low $\delta$ values. The aromatic and the carbonyl carbon atoms appeared at high $\delta$ values. This is because the aromatic ring is electron withdrawing and the aromatic carbons are highly deshielded and resonate at high frequency. The electronegative effect of the oxygen atom on the carbonyl group makes the carbonyl carbon to appear at higher $\delta$ value.

Table 4 lists the $\mathrm{m} / \mathrm{z}$ (relative abundance, \%) values of principal fragments of the studied compound, while figure 1 illustrates the mass spectrum of the compound. The mass spectrum of the compound shows a molecular ion of $\mathrm{m} / \mathrm{z} 235$ corresponding to the molecular mass of the compound. The molecular ion of $\mathrm{m} / \mathrm{z} 235$ fragment to give $\mathrm{m} / \mathrm{z} 220$ by loss of -NH group. The ion of m/z 220 was broken to give $\mathrm{m} / \mathrm{z} 206$ by losing $\mathrm{CH}_{2}$ group and fragment to $\mathrm{m} / \mathrm{z} 177$ by loss of HCO. This fragmented to $\mathrm{m} / \mathrm{z} 162$ by loss of $-\mathrm{CH}_{3}$ group and then $\mathrm{m} / \mathrm{z} 136$ by loss of $\mathrm{CN}$ group. The loss of $\mathrm{O}$ gave $\mathrm{m} / \mathrm{z}$ 120 which fragment to give $\mathrm{m} / \mathrm{z} 93$ by loss of $-\mathrm{HCN}$ and finally gave $\mathrm{m} / \mathrm{z} 65$ by loss of $\mathrm{CO}$ group.

\section{Conclusion}

The present work shows that the mass spectra of compound 2 has relatively small molecular ion and peaks typical of a cleavage and rearrangement processes type fragmentation. Compound 2 give a characteristic fragmentation pattern with a very stable fragment of benzopyrazolone $(\mathrm{m} / \mathrm{z} 235)$. 


\section{Acknowledgements}

The authors appreciate the assistance of Dr. Marvis E, in England for running the spectra.

\section{References}

[1] Finar IL. (2007). Organic chemistry Volume 1, $6^{\text {th }}$ Edition. P. 826.

[2] Wikipedia, foundation. (2008). "Anti-inflammatory agents". http://en.wikipedia.org/wiki/anti-inflammatory. Access 7, April, 2006.

[3] Wikipedia. (2010). Quinazolinone encyclopedia. http://en.wikipedia.org/wiki/quinazoline. Access 27, April, 2006.

[4] ShradhaSinha, Scrivastava, M. (1994). Cardiotonic, antihistamine, anti-fungal, antiviral, antimycobacteria and antimalarial activities of quinazolinone alkaloids. Prog. Drug Res. 43, 143.

[5] Molina, P. Teraga, A. Gonzalez-Tejero, A. (2001). Antiinflammatory Activity of some quinazolinone alkaloids.

[6] Scrivatva, B. M.; Bhalla, V. K.; Shankar, T. N. (1993). Analgesic activity of some quinazolinone alkaloids. ArzneimForsch. 43, 596-600.

[7] Hour MJ, Huang LJ, KuoSc, Xia Y, Bastow K, Nakanishi Y, Hamel E, Lee KH. (2000). 6-Alkylamino and 2, 3-dihydro-3methoxy-2-phenyl-quinazolinone and related compounds: their synthesis, cytotoxicity and inhibition of tubulin polymerization. J. Med. Chem. 43, 4479-4487.

[8] Hamel E, Lin CM, Ploueman J, Wang HK, Lee Kh, Paull KD. (1996). Antitumor Activities of 2, 3-dihydro-2(aryl)-4(1H)quinazolinone derivatives. Interactions with tubulin. Biochem. Pharmacol. 51, 53-59.
[9] Mayer, J. P.; Lewis, G. S. Curtis M. J.; Zhang. (1997). Antidiabetic activity of some quinazolinone alkaloids. $J$. Tetrahedron Lett. 389, 8445.

[10] Jiang J. B. Hessan, D. P: Dusac; Dexter, D. L. Kag, G. J. Hamel, E. (1990). Anti-diabetic activity of some quinazolinone alkaloids. J. Med. Chem. 33, 1721.

[11] A. Czarnik; Acc. Chem. Res, 1996, 29, 112.

[12] A. Kozikowski; Comphrensive Heterocyclic Chemistry, Pergamon Press, 1984, 1,567.

[13] Amar R. Desai and Kishor R. Desai, Niementowski reaction: microwave induced and conventional synthesis of quinazolinones and 3-methyl-1H-5-pyrazolones and their antimicrobial activity, ARKIVOC (xiii), 2005, 98-108.

[14] Sachin S. Laddha, Satyendra p. Bhatnagar, A new therapeutic approach in Parkinson's disease: some novel quinazoline derivatives as dual selective phosphodiesterase 1 inhibitors and anti-inflammatory agents. Bioorganic \& Medicinal Chemistry Letters, 17, 2009, 6796-6802.

[15] Abdel-Rahman AE, Bakhite EA, Al-Taifi EA. Synthesis and antimicrobial testing of some new Ssubstituted-thiopyridines, thienopyridines, pyridothienopyrimidines and pyridothienotriazines. Pharmazie 2003; 58: 372-377.

[16] Chambhare, RV, Khadse BG, Bobde AS, Bahekar RH. Synthesis and preliminary evaluation of some N-[5- (2furanyl)-2-methyl-4-oxo-4H-thieno[2,3-d]pyrimidin-3-yl]carboxamide and 3-substituted-5- (2-furanyl)-2-methyl-3Hthieno[2,3-d]pyrimidin-4- ones as antimicrobial agents. Eur J Med Chem 2003; 38: 89-100.

[17] Santagati NA, Caruso A, Cutuli VMC, Caccamo F. Synthesis and pharmacological evaluation of thieno[2,3-d]pyrimidin2,4-dione and 5H-pyrimido [5,4-b]indol-2,4-dione derivatives. IlFarmaco 1995; 50: 689-695. 